\title{
PENERAPAN METODE EKSTRAKSI WAVELET HAAR UNTUK DETEKSI GERAKAN SANDI SEMAPHORE MENGGUNAKAN STICK LALU LINTAS
}

\author{
Moch. Hatta ${ }^{1}$, Nanda Very Mulyono ${ }^{2}$, R. Dion Handoyo Ontoseno ${ }^{3}$ \\ 1,3Teknik Komputer, Fakultas Teknik \\ ${ }^{2}$ Teknik Informatika, Fakultas Teknik \\ Universitas Maarif Hasyim Latif, Sidoarjo, Indonesia \\ e-mail : ${ }^{1}$ moch.hatta@dosen.umaha.ac.id, ${ }^{2}$ nanda-very-mulyono@student.umaha.ac.id, \\ 3dion.seno@dosen.umaha.ac.id
}

Diterima: 24 April 2020. Disetujui : 20 Juni 2020. Dipublikasikan : 30 Juni 2020

(C)2020 -TESJ Fakultas Teknik Universitas Maarif Hasyim Latif. Ini adalah artikel dengan

akses terbuka di bawah lisensi CC BY 4.0 (https://creativecommons.org/licenses/by/4.0/)

\begin{abstract}
ABSTRAK
Semaphore, salah satu dari beberapa cara alternatif yang telah digunakan sejak lama untuk berkomunikasi tanpa mengeluarkan suara, melainkan menggunakan bendera ataupun tangan kosong dengan cara menentukan posisi dan derajat sudut yang dibentuk oleh kedua tangan. Semaphore sering digunakan untuk berkirim pesan maupun informasi. Pada jaman perang dunia dulu semaphore digunakan untuk mengirim informasi perang melalui rel kereta api. Sekarang semaphore lebih sering digunakan sebagai bahan pembelajaran pada kegiatan seperti pramuka dan kegiatan pada alam liar. Sistem untuk mendeteksi gerakan sandi semaphore ini, akan menggunakan kamera handphone dengan resolusi sebesar 13 megapixel untuk mengambil gambar peraga gerakan sandi semaphore serta menggunakan laptop untuk melakukan serangkaian proses deteksi. Dalam sistem terdapat beberapa tahapan yang antara lain segmentasi, ekstraksi wavelet haar dan jarak euclidean kemudian output dalam bentuk huruf abjad. Sistem deteksi gerakan sandi semaphore ini telah berjalan dengan baik. Sistem dapat mendeteksi gerakan peraga pada variasi jarak 10 meter, 15 meter, dan 20 meter dengan persentasi keberhasilan kumulatif yang mencapai $85 \%$.
\end{abstract}

Kata kunci : ekstraksi wavelet haar; euclidean; segmentasi; semaphore

\section{PENDAHULUAN}

Pramuka atau yang lebih dikenal dengan praja muda karana adalah sebuah organisasi pendidikan nonformal yang menyelenggarakan suatu kegiatan yang lebih sering dan lebih cocok diadakan di luar ruangan, salah satu ilmu dari banyaknya ilmu yang bisa kita pelajari dari pramuka adalah sandi semaphore, sandi ini adalah suatu cara untuk mengirim dan menerima serta berkomunikasi menggunakan bendera, batang pohon, ataupun juga dengan tangan kosong. Informasinya bisa diartikan melalui posisi tangan atau alat yang ada pada kedua tangan peraga dan posisi tubuh.

Pada era digital seperti saat ini sandi semaphore terkadang sulit untuk diterjemahkan bila orang tersebut masih awam apalagi bila belum pernah mengikuti pramuka. Padahal materi sandi semaphore bisa kita gunakan untuk kehidupan sehari-hari contohnya saat kita diharuskan untuk berkomunikasi dengan banyak orang dan dengan jarak yang relatif jauh tentunya ketika alat komunikasi lain tidak bisa digunakan seperti handphone dan walkie talkie, berkomunikasi dengan suara juga tidak akan efektif karena hanya yang jaraknya dekat yang mendengar secara jelas sementara yang jaraknya jauh pasti tidak akan mendengar dengan jelas atau bahkan mungkin tidak mendengarnya. Pada situasi seperti ini semaphore sangat berguna untuk menyampaikan pesan lewat gerakan yang bisa dilihat oleh banyak orang.

Karena hal beberapa hal tersebut penulis ingin untuk membuat sebuah aplikasi yang dapat digunakan untuk menerjemahkan gerakan semaphore ke dalam bentuk huruf dengan bantuan algoritma juga tentunya, agar orang yang awam dapat mengartikan gerakan semaphore dalam sandi semaphore. Dalam aplikasi ini penulis mengambil gambar gerakan semaphore dari peraga kemudian menerjemahkannya dengan menggunakan metode ekstraksi wavelet kemudian menghitung jaraknya antar gambar yang diambil dengan gambar yang ada dalam basis data menggunakan euclidean dan akhirnya menentukan output huruf abjad dari A sampai Z. Dalam pengambilan gambar disini peraga akan menggunakan 2 stick lalu lintas yang ada pada kedua tangannya kemudian memperagakan 
gerakan sandi semaphore huruf abjad dari huruf a sampai huruf $\mathrm{z}$ dengan 3 variasi jarak yaitu 10 meter, 15 meter, dan 20 meter.

\section{METODOLOGI PENELITIAN}

Pada bagian berikut ini penulis akan membahas mengenai metode penelitian yang akan digunakan pada sistem deteksi gerakan sandi semaphore menggunakan stick lalu lintas dengan metode ekstraksi wavelet haar. Untuk dapat mencapai hasil yang akurat dan maksimal, maka akan melalui beberapa tahapan proses yang terstruktur. Tahapannya akan ditampilkan seperti diagram alir pada Gambar 1.

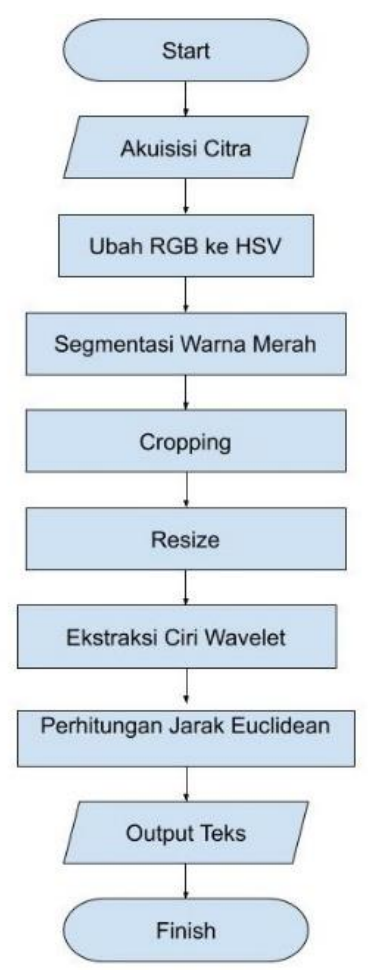

Gambar 1 Diagram Alir Proses Deteksi

Pada Gambar 1 adalah proses dalam perancangan sistem deteksi gerakan sandi semaphore menggunakan stick lalu lintas. Sistem ini memiliki beberapa tahapan seperti yang sudah ada pada gambar. Proses tahapannya akan dilalui oleh gambar secara berurutan, alasannya adalah agar didapatkan hasil yang akurat. Sistem akan dimulai dengan akuisisi citra pada jarak 10 meter, 15 meter, 20 meter selanjutnya citra akan diubah ke HSV dan dilakukan segmentasi warna merah sesuai warna stick lalu lintas pada kanal Hue. Setelah proses segmentasi berhasil kemudian akan berlanjut pada cropping dan resize, dimana hasil dari resize akan diekstraksi menggunakan metode wavelet haar dan langkah terakhir adalah melakukan perhitungan jarak antara citra uji dan citra basisdata menggunakan euclidean agar dapat mengeluarkan output berupa huruf yang sesuai.

\section{Wavelet Haar}

Metode yang digunakan oleh penulis adalah dengan menggunakan metode wavelet haar yang dalam prinsipnya akan dilakukan dengan 2 tahap yaitu konvolusi dan juga low pass filter. Konvolusi akan dilakukan dalam 2 dimensi yang membuat konvolusi akan dilakukan 2 kali yaitu konvolusi pada baris dan juga konvolusi pada kolom yang akan dilakukan secara saling bergantian. Metode wavelet haar ini juga hanya akan menggunakan 1 filter yaitu low pass filter dekomposisi, tujuannya antara lain karena penulis hanya ingin mendapatkan bentuk dasar dari suatu citra.

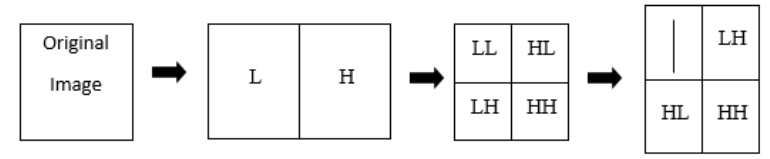

Gambar 2. Ilustrasi Wavelet Haar

\section{HASIL DAN PEMBAHASAN}

Bagian ini akan membahas mengenai interface program, penjelasan mengenai alur pada sistem program, dan pengujian yang dilakukan telah dilakukan oleh penulis. Hasil pengujian dari sistem deteksi semaphore ini juga akan dijabarkan lebih lanjut secara mendetail, begitu pula tentang keberhasilan dan keakuratan program ini dalam mendeteksi gerakan sandi semaphore. Gambar 3 adalah awal tampilan dari sistem ini.

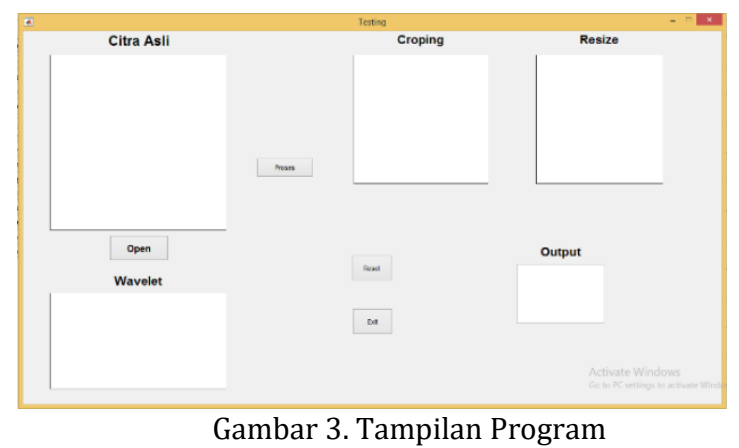

Gambar 3 adalah tampilan awal program dari sistem deteksi gerakan sandi semaphore. Tampilan awal ini akan ditemui ketika pertama kali menjalankan program ini. Pada tampilan awal ini terlihat beberapa axes untuk menampilkan hasil gambar pada tiap tahapnya masing-masing, pada axes citra asli akan muncul citra hasil akuisisi citra, kemudian pada axes cropping akan muncul citra hasil segmentasi yang telah dilakukan cropping, selanjutnya pada axes resize akan muncul citra hasil cropping yang telah diresize dan terakhir pada axes wavelet akan muncul citra hasil ekstraksi 
wavelet haar. Dalam tampilan sistem juga terdapat beberapa tombol antara lain ialah tombol open untuk membuka folder pada komputer dan memilih foto mana yang akan dideteksi, kemudian tombol proses yang berfungsi untuk melakukan seluruh proses deteksi citra sampai menghasilkan output berupa huruf, lalu tombol reset adalah tombol untuk menghapus semua gambar yang terdapat dalam semua axes begitu pula dengan hasil output berupa huruf dan terakhir tombol exit yang tentunya berfungsi untuk keluar dari sistem.

Tombol proses yang ada pada tampilan sistem terdapat seluruh proses dalam pengolahan citra sampai diketahui hasil outputnya, dibawah akan dijelaskan mengenai alur tahapan yang dilewati oleh gambar sampai akhirnya dapat mengeluarkan output berupa huruf.

\section{Segmentasi Citra}

Tahap proses deteksi sandi gerakan semaphore adalah melakukan segmentasi citra, namun dalam proses segmentasi terdapat beberapa tahap yang perlu dilalui oleh citra terlebih dulu agar mendapatkan hasil deteksi yang baik dan juga memiliki tingkat keakuratan yang tinggi. Tahap pertama yaitu dengan mengubah citra asli RGB menjadi Citra HSV, berikutnya akan disajikan contoh gambar awal dan setelah diubah ke HSV.

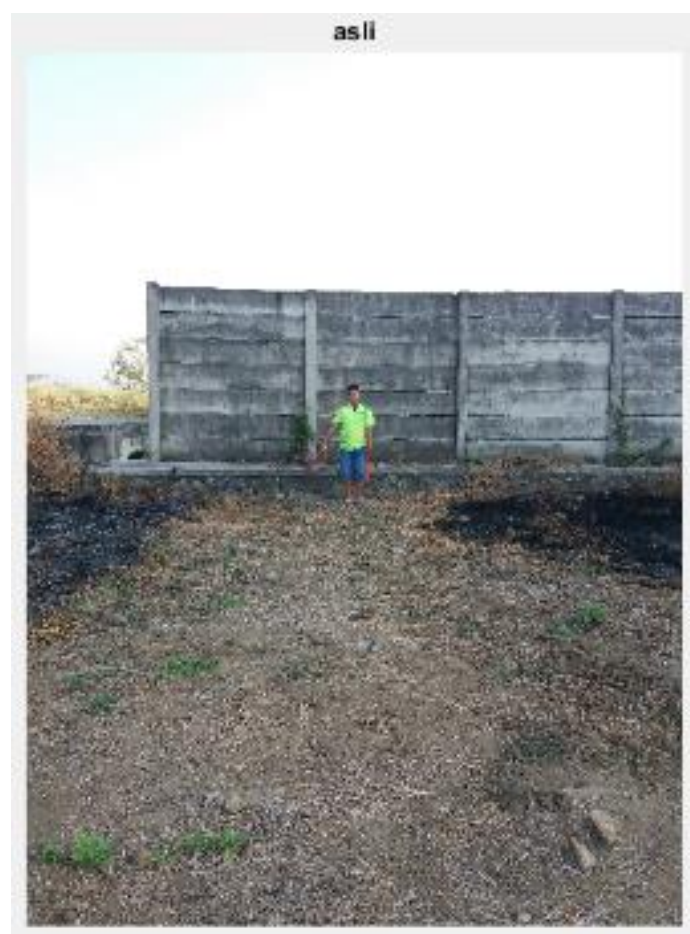

Gambar 4. Citra Asli

Gambar 4 adalah salah satu contoh citra asli pada variasi jarak 10 meter, gambar ini akan muncul dalam axes citra asli setelah menekan tombol open dan memilih gambar yang ingin dideteksi. Selanjutnya berikut ini disajikan Gambar 5 setelah dilakukan konversi dari RGB ke HSV.

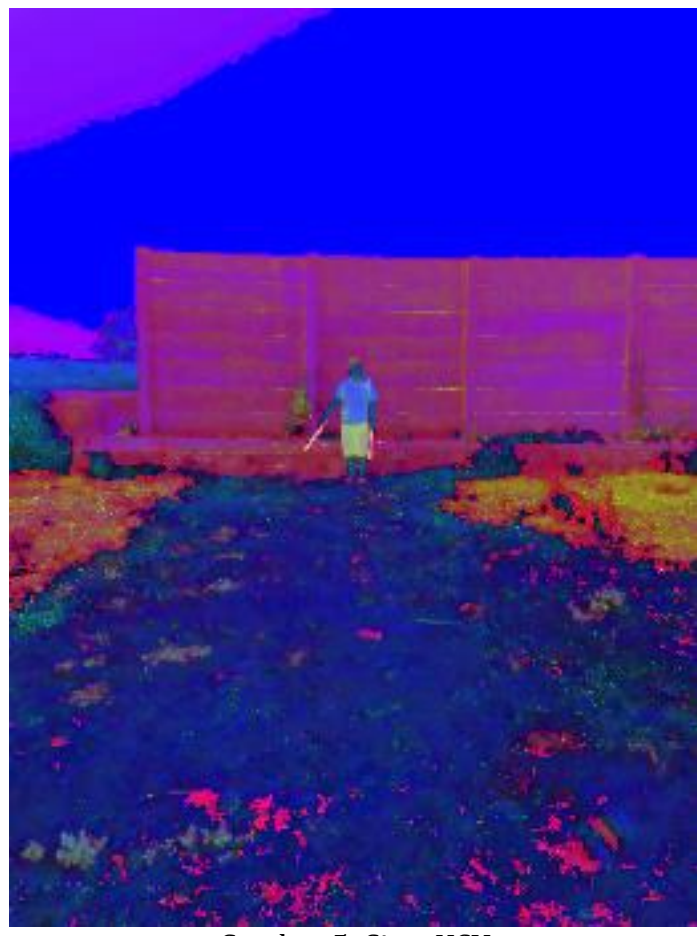

Gambar 5. Citra HSV

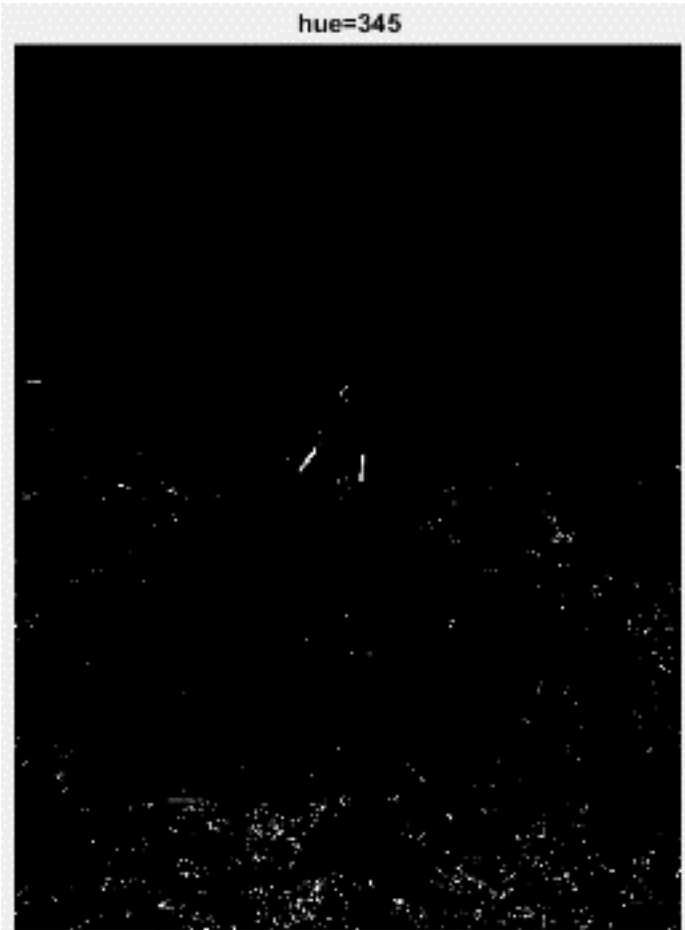

Gambar 6. Citra Hue Nilai > 345

Setelah citra asli RGB dikonversikan ke HSV langkah selanjutnya akan dilakukan segmentasi warna merah pada kanal hue. Caranya adalah dengan mengambil warna merah sesuai dengan warna stick lalu lintas pada kanal hue yang berada pada rentang nilai antara $>345$ dan $<360$. Ambil 
nilai citra pada kanal hue sebesar > 345 seperti pada contoh Gambar 6.

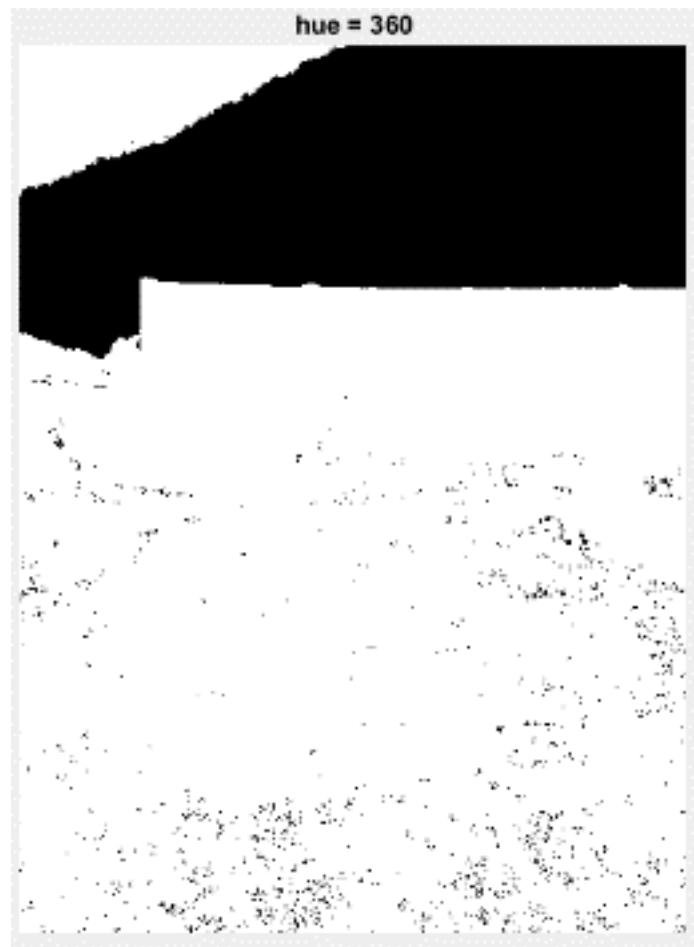

Gambar 7. Citra Hue Nilai $<360$

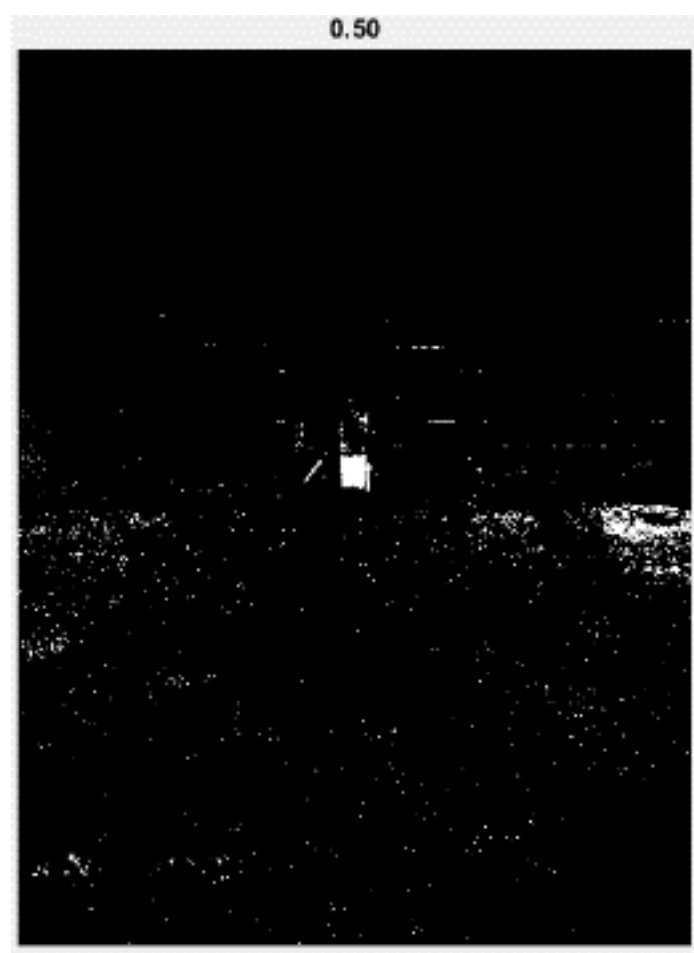

Gambar 8. Citra Saturation Nilai > 0.50

Kemudian ambil warna merah pada kanal hue dengan nilai sekitar $<360$ dan contoh gambarnya akan disajikan pada Gambar 7.

Langkah selanjutnya adalah dengan mengambil nilai pada kanal saturation pada nilai $>0.50$ contoh gambarnya akan ditampilkan pada Gambar 8.
Langkah terakhir untuk melakukan segmentasi warna merah adalah dengan menggabungkan ketiganya menjadi satu. Contoh gambarnya akan ditampilkan seperti Gambar 9.

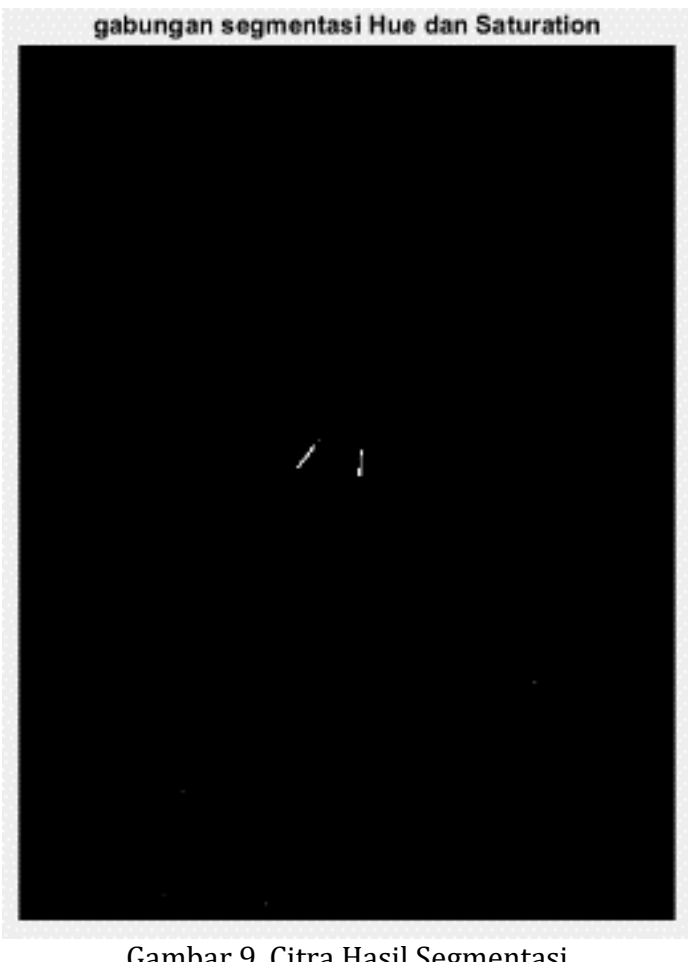

\section{Cropping}

Tahap cropping akan dilakukan setelah tahap segmentasi selesai dilakukan. Cropping ialah tahap pemotongan gambar hasil segmentasi sehingga citra yang didapat akan terfokus hanya pada posisi gerakan semaphore stick lalu lintas. Ukuran cropping pun akan tepat pada citra hasil segmentasi, sehingga akan mendapatkan hasil yang presisi. Citra hasil cropping ini akan ditampilkan dalam axes cropping pada sistem deteksi gerakan sandi semaphore. Hasil gambarnya akan disajikan pada Gambar 10.

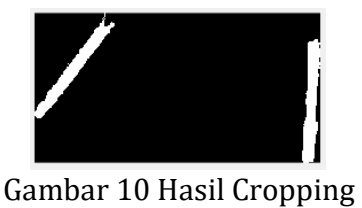

\section{Resize}

Tahap resize akan secara otomatis membuat ukuran gambar dari hasil cropping berubah menjadi 64 x 64 piksel. Proses ini akan menjadikan semua citra hasil cropping seragam atau bisa dibilang tahap ini berfungsi untuk membuat semua citra memiliki ukuran yang sama agar dalam basisdata semua gambar memiliki ukuran yang seragam sehingga tidak membingungkan. Citra ini 
akan ditampilkan dalam axes resize pada sistem deteksi gerakan sandi semaphore.

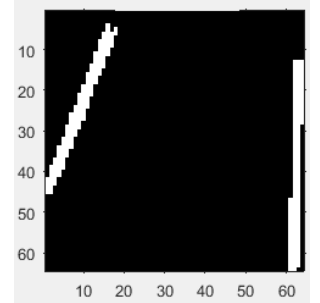

Gambar 11 Hasil Resize

\section{Ekstraksi Wavelet}

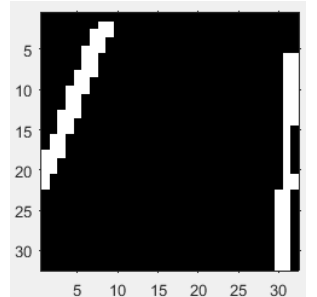

Gambar 12. Hasil Ekstraksi Wavelet Haar

Ini merupakan tahapan terakhir yang harus dilalui oleh citra agar dapat menghasilkan deteksi yang akurat yaitu adalah Ekstraksi Wavelet, disini penulis akan menggunakan metode Wavelet Haar dikarenakan ini adalah jenis wavelet yang paling sederhana dengan menggunakan konvolusi serta Low Pass Filter. Hasil dari Ekstraksi Wavelet ini akan diperkecil lagi ukurannya menjadi 32x32 piksel untuk memperkecil ukuran gambar dan mempercepat proses komputing. Hasil ekstraksi

Tabel 1. Hasil Deteksi Peraga 1

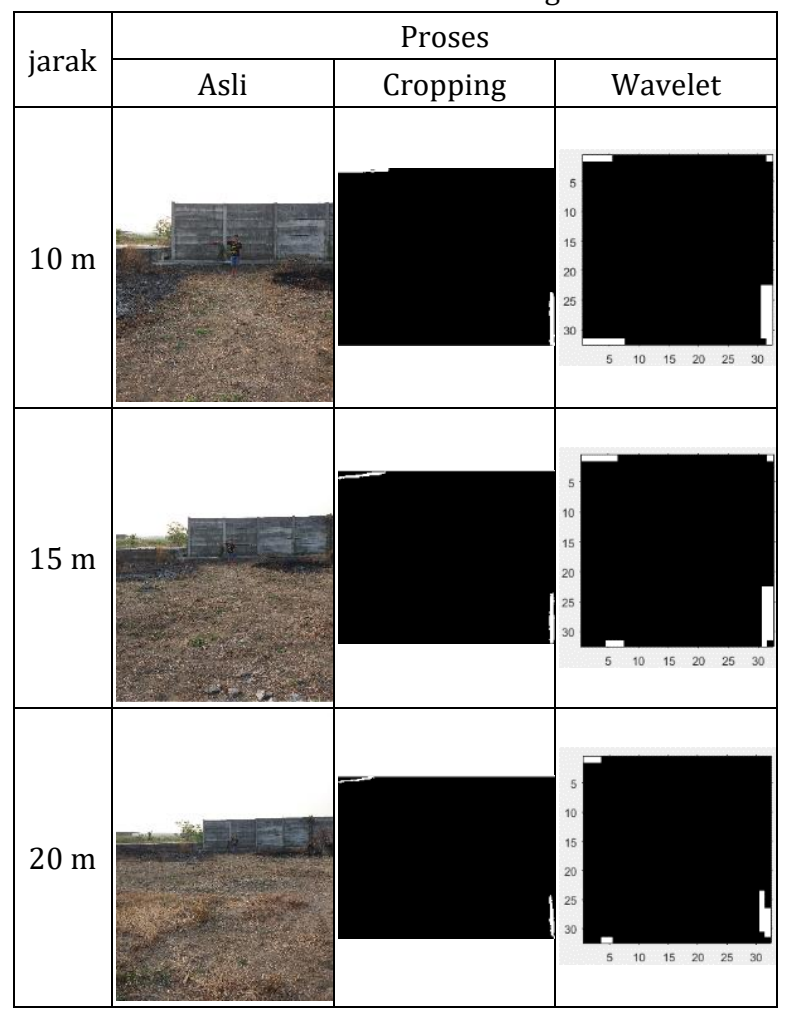

wavelet haar ini akan ditampilkan dalam axes wavelet seperti pada tampilan sistem. Hasil citra dari tahap ini akan ditunjukkan pada Gambar 12.

Setelah semua tahapan proses dilakukan dengan benar dan berurutan, maka hasil dari deteksi gerakan semaphore menggunakan stick lalu lintas akan didapatkan. Perlu diketahui bahwa hasil pada tiap variasi jaraknya antara lain pada 10 meter, 15 meter, dan 20 meter akan berbeda satu sama lain tergantung pada jarak dan cahaya yang didapat saat pengambilan gambar. Hasil dari tiap proses akan disajikan oleh Tabel 1 dengan 2 peraga berbeda dan variasi jarak.

Pada Tabel 1 adalah contoh sampel dari pengujian sistem deteksi gerakan sandi semaphore oleh peraga pertama. Huruf yang diuji dalam tabel di atas adalah huruf $b$ yang diuji pada 3 variasi jarak. Tiap variasi jarak akan menghasilkan tiap hasil deteksi yang berbeda seperti pada Tabel 1 .

Pada Tabel 2 adalah contoh sampel pengujian dari peraga kedua dengan huruf yang diuji adalah huruf a. Bisa dilihat perbedaan antara gambar croppping dan wavelet yang berbeda bentuk, itu adalah manfaat dari penggunaan proses resize yang membuat semua gambar memiliki ukuran piksel yang seragam sehingga memudahkan pengguna untuk memahami tiap gambarnya. Dari Tabel 1 dan Tabel 2, kita lihat pada tiap variasi jarak stick lalu lintas dapat terdeteksi meskipun dengan hasil yang bervariasi pula tergantung pada jarak dan juga pada cahaya yang didapat oleh stick lalu lintas. Berdasarkan

Tabel 2. Hasil Deteksi Peraga 2

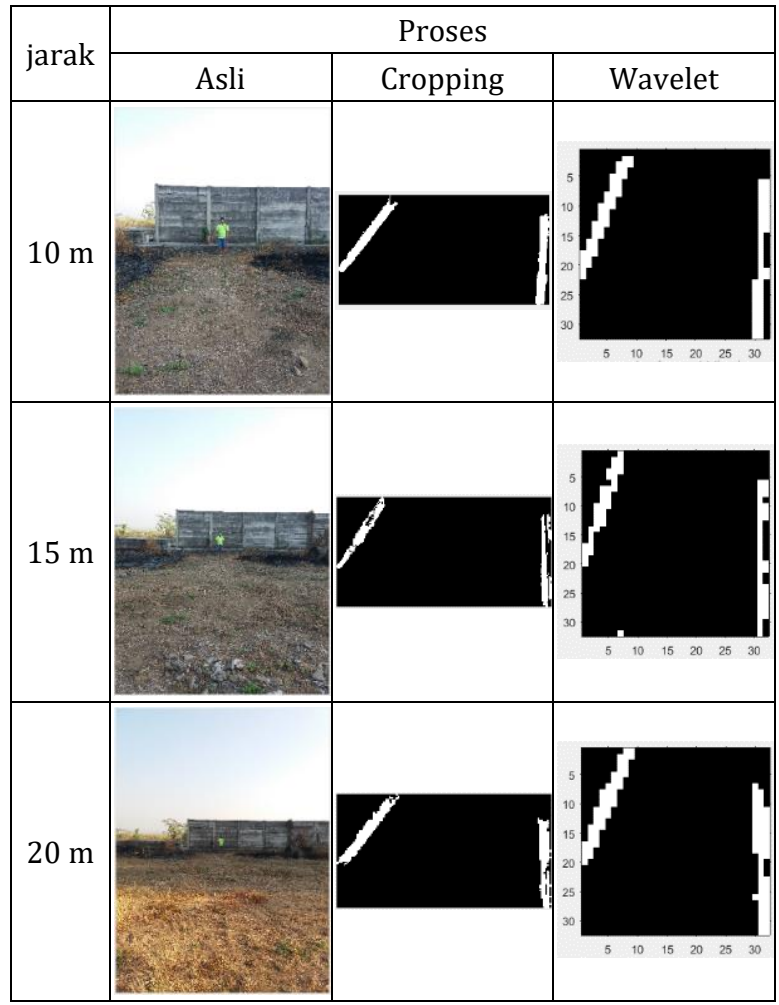


pada ketiga variasi jarak yaitu pada 10 meter, 15 meter, dan 20 meter, hasil dari akurasi sistem pun dapat dihitung.

Dari hasil percobaan yang dilakukan dengan menggunakan 4 peraga yang berbeda dengan rincian tiap peraga akan mempergakan gerakan semaphore dari a sampai z dengan 3 variasi jarak. Jadi tiap peraga akan memiliki 78 pose gambar gerakan sandi semaphore. Kemudian 156 gambar dari 2 orang peraga akan jadi citra latih dan masuk dalam database sementara 156 gambar dari 2 peraga yang lain akan jadi citra uji.

Tabel 3. Keberhasilan Ujicoba

\begin{tabular}{c|c|c|c}
\hline Jarak & Jumlah Uji & Berhasil & Gagal \\
\hline 15 meter & 52 & 49 & 3 \\
\hline 10 meter & 52 & 45 & 7 \\
\hline 20 meter & 52 & 39 & 13 \\
\hline Jumlah & $\mathbf{1 5 6}$ & $\mathbf{1 3 3}$ & $\mathbf{2 3}$ \\
\cline { 2 - 4 } & &
\end{tabular}

Berdasarkan Tabel 3 dapat disimpulkan bahwa keakuratan pada sistem gerakan sandi semaphore semakin turun bila jaraknya semakin jauh, bisa dipahami dari jumlah kegagalan pada variasi jarak 20 meter lebih banyak daripada variasi jarak 15 meter begitupun juga pada variasi jarak 10 meter yang memiliki jumlah kegagalan yang paling sedikit, sehingga dari tabel diatas dapat dihitung persentase keberhasilan dari sistem deteksi sandi semaphore dengan hasil kumulatif dari 3 variasi jarak yaitu pada 10 meter, 15 meter, dan 20 meter mencapai hampir 85\%.

\section{PENUTUP}

Berdasarkan hasil pengujian dari pada program deteksi semaphore maka kesimpulan yang dapat diambil bahwa sistem ini dapat berjalan dengan baik namun tentunya dengan beberapa syarat seperti background yang warnanya diharapkan berbeda dengan warna stick lalu lintas agar mendapat hasil segmentasi yang baik serta memperhatikan intensitas cahaya yang mampu dipantulkan oleh stick (tempat yang teduh). Sistem ini akan berjalan lebih akurat bila jarak citra tidak terlalu jauh, jadi bisa disimpulkan bahwa bila semakin dekat jarak pengambilan gambar maka akan semakin baik akurasi deteksi yang didapat begitu juga sebaliknya, bila jaraknya makin jauh maka keakuratannya pun semakin berkurang.

Program ini pun menggunakan basis data sebagai pembanding dengan citra uji yang akan diproses, dapat disimpulkan bila semakin banyak basisdata yang dimiliki maka hasil keakuratan dari system ini pun kemungkinan juga akan membaik. Persentase hasil ujicoba menandakan bila program ini masih bisa untuk dikembangkan lagi agar akurasinya menjadi semakin baik.

\section{DAFTAR PUSTAKA}

Adiwilaga, A. (2014). Teori Pengukuran Jarak | Anugrah Adiwilaga Blogs. Retrieved November 6, 2018, from https://blogs.itb.ac.id/anugraha/2014/09/ 10/teori-pengukuran-jarak/

Alam, D. (2014). Kompresi Citra Berwarna Menggunakan Transformasi Wavelet. Jurnal Matematika Integratif, 10(1), 55-62.

Fauzan, A. (2015). Ruang Warna Hue Saturation Value (HSV) serta Proses Konversinya - Kita Informatika. Retrieved November 6, 2018, from

http://www.kitainformatika.com/2015/01/ ruang-warna-hue-saturation-value-hsv.html

Hatta, M., Susrama, I. G., Purnama, I. K. E., \& Hariadi, M. (2016). Cacah Spermatozoa Menggunakan Background Segmentation dan Boundary Detection. SCAN - Jurnal Teknologi Informasi Dan Komunikasi, 11(1), 67-74.

Masrani, H., \& Ilhamsyah, I. R. (2018). Aplikasi Pengenalan Pola pada Huruf Tulisan Tangan Menggunakan Jaringan Saraf Tiruan dengan Metode Ekstraksi Fitur Geometri. Coding Jurnal Komputer Dan Aplikasi, 6(2).

Pamungkas, A. (2015). Segmentasi Citra । Pemrograman Matlab. Retrieved November 6, 2018, from https://pemrogramanmatlab.com/pengolah an-citra-digital/segmentasi-citra/

Putra, I. W. S. E. (2016). Klasifikasi Citra Menggunakan Convolutional Neural Network (CNN) pada Caltech 101 (Institut Teknologi Sepuluh Nopember). Retrieved from http://repository.its.ac.id/48842/

Putra, L. S. A. (2017). Pengenalan Kode Huruf Sempahore. Universitas Sanata Dharma.

Riadi, M. (2016). Pengolahan Citra Digital KajianPustaka.com. Retrieved November 6, 2018, from https://www.kajianpustaka.com/2016/04/ pengolahan-citra-digital.html

Sianipar, R. H., Mangiri, H. S., \& Wiryajati, I. K. (2013). MATLAB untuk Pemrosesan Citra Digital. Bandung: Penerbit Informatika. 